\title{
Finite Element Analysis of Aircraft Radial Engineconnecting Rod Using Composite Material
}

\author{
M.K.Karthik ${ }^{1}$, N.Kalaimani ${ }^{2}$, P.S.Mohanasaravanan ${ }^{3}$ \\ 1, 2,3 Assistant Professor, Department of Aeronautical Engineering, Bharath Institute of Higher Education and \\ Research, Chennai.
}

Article History: Received: 11 January 2021; Accepted: 27 February 2021; Published online: 5 April 2021

\begin{abstract}
The main objective of this project is analysis of Aircraft radial engine connecting rod by using fiber matrix composite materials in this type of composite materials to improve their ductility properties aluminium metal powder will be added in the matrix components like epoxy resin elements from the resin considerations the metal powder will be $5-10 \%$ of the weight of aluminium powder only added, the comparison of the existing material with GFRP Reinforced aluminium powder and Pure GFRP Material from the comparison of stress, strain and deformation results from the ANSYS Software GFRP with Aluminium powder material will get best results
\end{abstract}

Keywords: Aircraft, Radial Engine, Connecting rod, GFRP

\section{Introduction:}

In general connecting rods are available in the following types H-beam, I-beam or a combination of both. The choice of application of each type is based on their end application. Usually I-beam is having the advantage of light weight with high strength but the type of material used restricts its capacity to deal with heavy loads. At the same time an H-beam will withstand much more stress without bending. This property enables its usage in high power engines. The connecting rod used in engines are always will be induced a loading complex in nature [6]. It is subjected to fatigue load of the order of 108 to 109 cycles, ranging from combustion loads which are highly compressive in nature, to inertia loads which are mostly tensile loads. Because of this nature we should look for the durability of the component. [7]. Owing to importance of such level, the connecting rod has been provides scope for research in various aspects such as material technology, production methodology, performance simulation, fatigue, etc. In this current study, it is necessary to investigate finite element modeling techniques, optimization methods, recent trends in production technology, materials which are new, fatigue modeling, and manufacturing cost analysis.

The basic configuration of radial engine which is sub type of reciprocating type will be having the cylinders radiating in outward direction from a central crankcase which resembles the shape of spokes in a wheel. The top view of an engine will be resembling the shape of a star, hence it is named as a "star engine". Before the invention of gas turbine engines came into regular usage, radial engine type configuration was the most commonly used one.

Finite Element Modeling:

Preparation of model for the connecting rod is carried out by CATIA V5 software and then the specimen references are taken from the Cessna Aircraft radial engine the dimensions of the connecting rod is to the radial engine connecting rod dimensions

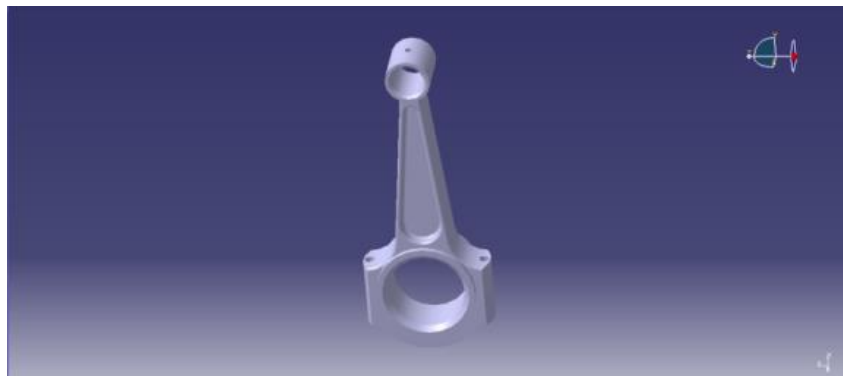

Fig No: $13 D$ model of Connecting Rod

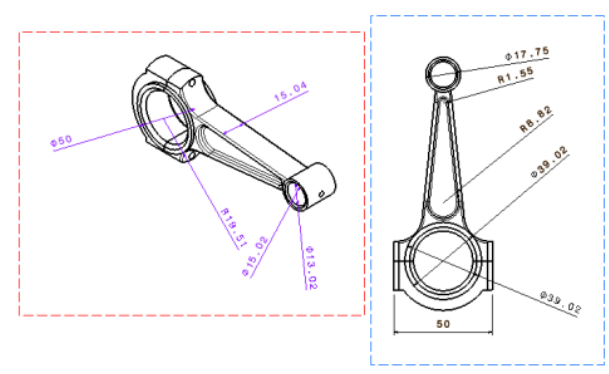

Fig No: 2 2D model of Connecting Rod 


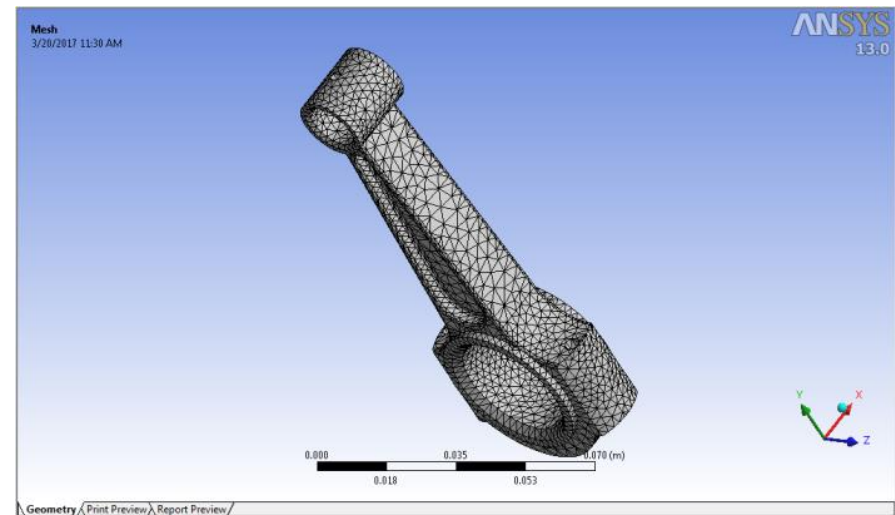

Fig No: 3 Mesh images of connecting rod

Results and Discussion:

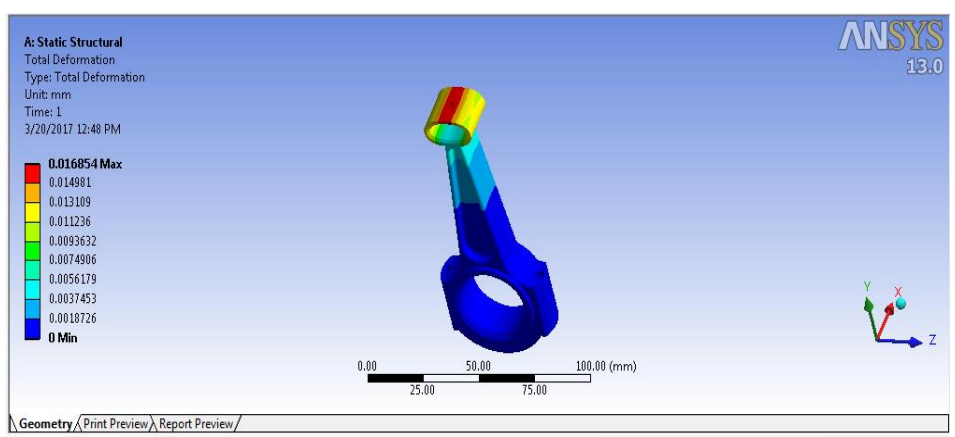

Fig No: 4 Total Deformation of Connecting Rod

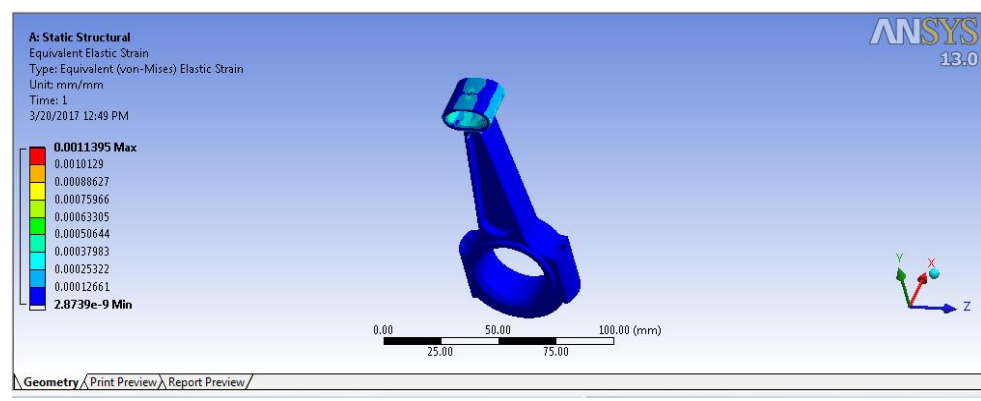

Fig No: 5 Strain of Connecting rod

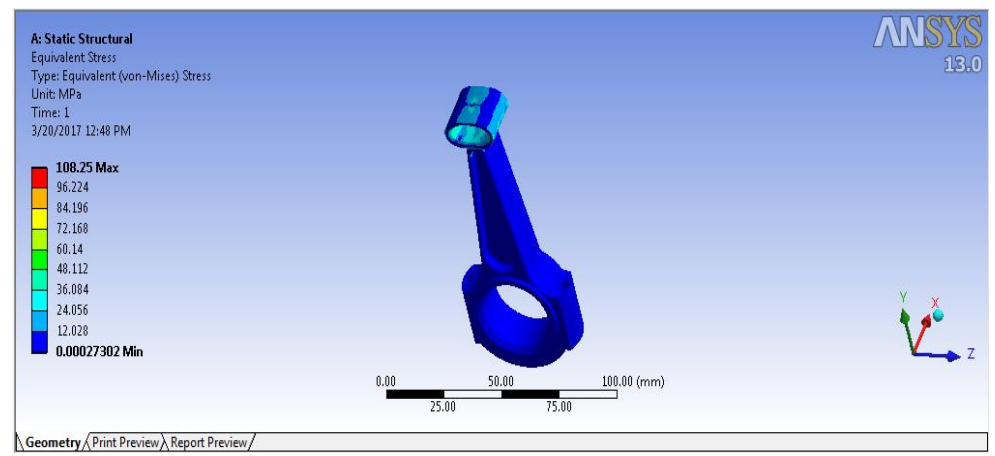

Fig No: 6 Stress on Connecting rod 


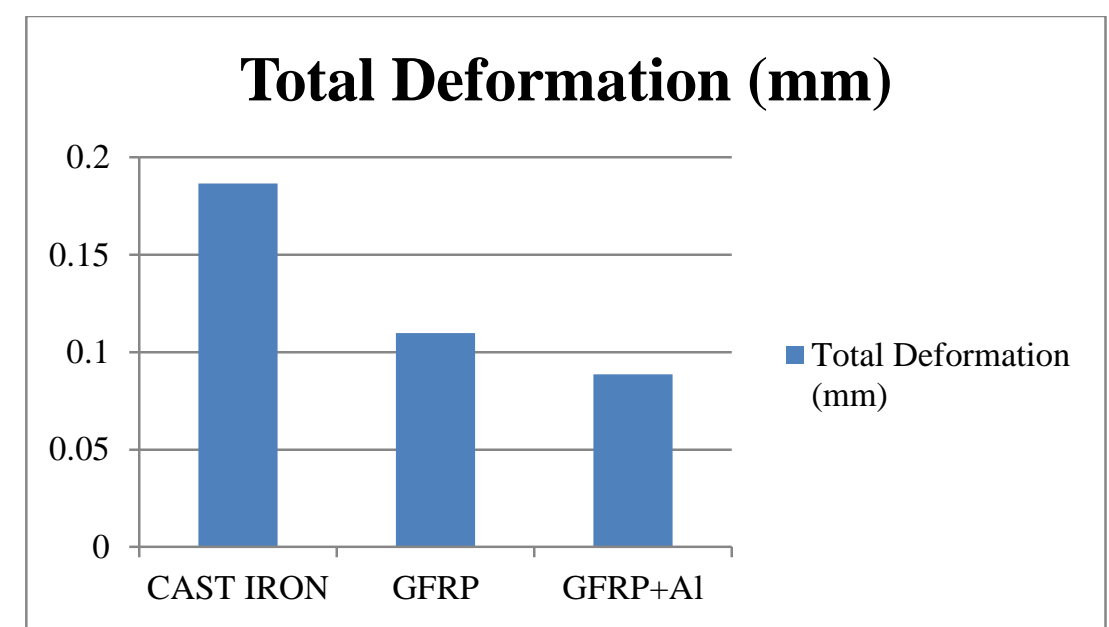

Fig No: 7 Comparison of Total deformation with various materials

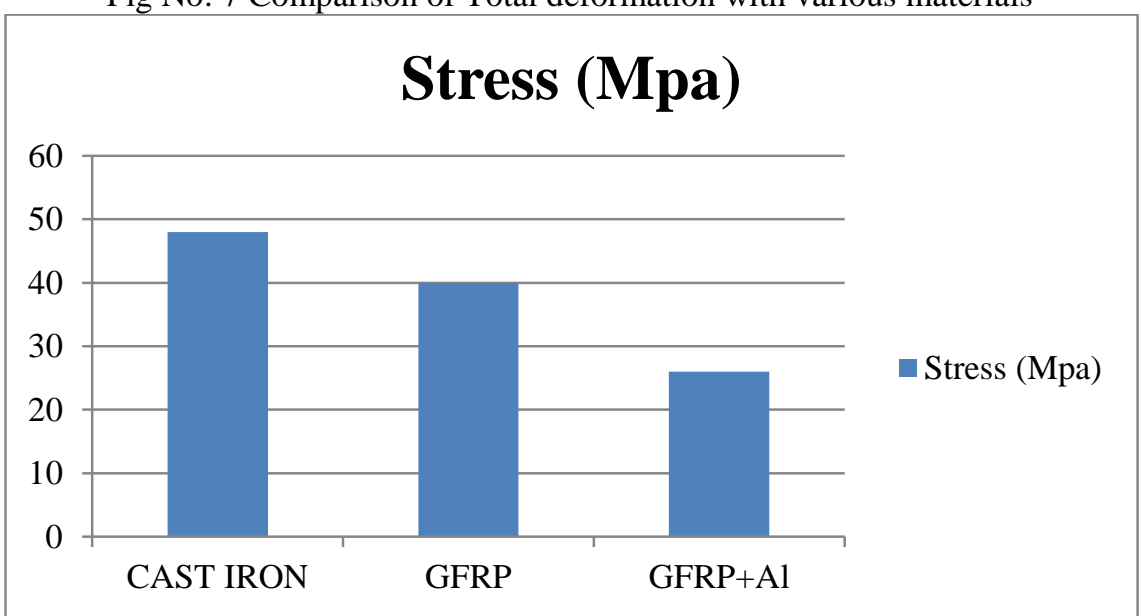

Fig No: 8 Comparison of stress with various materials

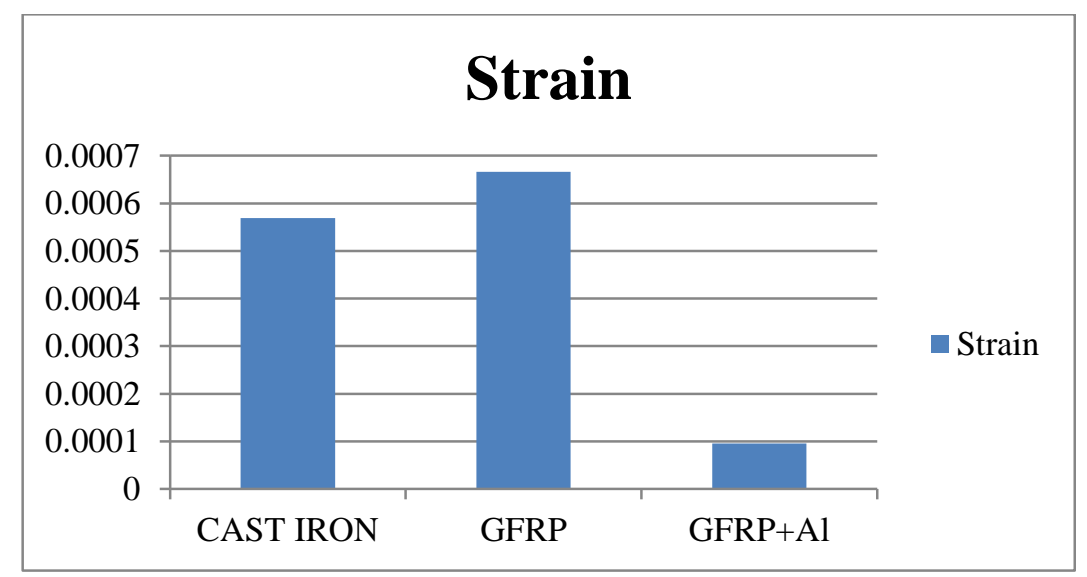

Fig No: 9 Comparison of Strain with various materials

\section{Conclusion:}

In our project aircraft radial engine connecting rod analysis using the cast iron and gfrp with aluminium powder composite materials in this project is loading condition is $1000 \mathrm{~N}$ is carried in two different materials cast iron and gfrp with aluminium powder composite materials in the stress analysis results of stress and deformation values are get the comparison of stress and deformation gfrp with aluminium powder composite materials the results are 
compared by stress values low stress producing material have the more life and carbide material have more strength so alternative material for connecting rod is gfrp with aluminium powder composite materials

\section{REFERENCES}

1. Balasubramaniam, B., Svoboda, M., and Bauer, W., 1991, "Structural optimization of I.C. engines subjected to mechanical and thermal loads," Computer Methods in Applied Mechanics and Engineering, Vol. 89, pp. 337-360.

2. Bhandari, V. B., 1994, "Design of Machine Elements," Tata McGraw-Hill. Clark, J. P., Field III, F. R., and Nallicheri, N. V., 1989, "Engine state-of-the-art a competitive assessment of steel, cost estimates and performance analysis," Research Report BR 89-1, Automotive Applications Committee, American Iron and Steel Institute.

3. Puran Singh, Debashis Pramanik, Ran Vijay Singh, "International Journal of Automotive Engineering and Technologies", Vol. 4, Issue 4, pp. 245-253,2015.

4. Mohammad Ranjbarkohan, Mohammad Reza Asadi and Behnam Nilforooshan Dardashti, Australian Journal of Basic and Applied Sciences, 5(12): 2084-2089, 2011.

5. Mohammad Reza Asadi Asad Abad, Mohammad Ranjbarkohan and Behnam Nilforooshan Dardashti Australian Journal of Basic and Applied Sciences, 5(12): 1830-1838, 2011.

6. R A Savanoor, Abhishek Patil, Rakesh Patil and Amit Rodagi, Int. J. Mech. Eng. \& Rob. Res. 2014 ,ISSN 2278 - 0149 Vol. 3, No. 3.

7. Ramani et al Int. Journal of Engineering Research and Applications, Vol. 4, Issue 3(Version 1), March 2014, pp.216- 220

8. Design and analysis of a connecting rod https://www.researchgate.net/publication/321964919_desi gn_and_analysis_of_a_connecting_rod,2018 